\title{
Determination of styrene content in Gorgonzola PDO cheese by headspace solid phase micro-extraction (HS-SPME) and gas-chromatography mass-spectrometry (GC-MS)
}

\author{
L. M. Chiesa • S. Panseri • S. Soncin • L. Vallone • \\ I. Dragoni
}

Published online: 12 May 2010

(C) Springer Science+Business Media B.V. 2010

\begin{abstract}
Control of the composition of products that are intended for use as packaging material is essential, particularly when these products come into direct contact with food. It is well known that plastics are not inert and that their residual monomers, starting substances, and additives are able to migrate into the food they contact. Among plastics, styrene is a common compound found in many plastic containers that can also be produced by the oxidation of Penicillium roqueforti used in gorgonzola Protected Denomination of Origin cheese manufacturing. Therefore, solid-phase microextraction combined with gas chromatography/mass spectrometry was applied in the present work to determine the styrene content in packaged and unpackaged gorgonzola cheese samples to understand styrene migration phenomena from plastic containers.
\end{abstract}

Keywords Penicillium spp . Styrene $\cdot$ Cheeses $\cdot$ Headspace solid phase micro-extraction Gas-chromatography mass spectrometry

\begin{abstract}
Abbreviations
HS-SPME headspace solid phase micro-extraction

GC-MS gas-chromatography mass spectrometry
\end{abstract}

\section{Introduction}

Penicillium is one of the most common fungal genera in nature and is able to grow in different habitats. Penicillium are considered to be ubiquitous saprophytes with important uses in industrial mycology, especially for the production of antibiotics (penicillin, griseofulvin) and enzymes (ribonuclease) (Locci 1999). In the food industry, they play a role in the maturation of cheeses, such as Gorgonzola and Roquefort. Compared to other systematic groups, such as the Aspergillus genus, the genus Penicillium is characterized by

L. M. Chiesa $(\bowtie) \cdot$ S. Panseri $\cdot$ S. Soncin $\cdot$ L. Vallone $\cdot$ I. Dragoni

Dipartimento di Scienze e Tecnologie Veterinarie per la Sicurezza Alimentare, Università di Milano,

Via Celoria n. 10, 20133 Milano, Italy

e-mail: luca.chiesa@unimi.it 
a less marked xerophylia and lower adaptation to high temperatures. Some species are psychrotrophic and are capable of causing food spoilage at refrigeration temperatures, since they can grow, although slowly, at temperatures close to $0^{\circ} \mathrm{C}$. Furthermore, many species can produce mycotoxins (Frisvad and Filtenborg 1989; Adams and Yu 1998).

The saprophytic activity of fungi of the genus Penicillium can have a spoilage effect and cause unwanted changes in sensory characteristics (taste, odor, texture, appearance) or, conversely, give rise to "positive" characteristics of the substrate, as for cheese. In the latter case, the mold growth is essential for ensuring the quality of the product. In fact, inoculation of milk with pure starter cultures of Penicillium roqueforti, in some cases associated with Penicillium expansum, is used (Caridi 1996). These species can have a positive influence on the taste and the aroma of the finished product, due to an intense lipolytic activity towards triglycerides of milk (made by fungal lipase) with production of short chain carboxylic acids (acetic, butyric, caprylic, and caproic) and methylketones arising from enzymatic oxidation of carboxylic acids (Tiecco 2001). However, during the maturation of blue cheese, defects, such as the typical aroma of celluloid due to the production of styrene by Penicillium spp., can occur. These fungi are able to convert phenylalanine to cinnamic acid (a reaction catalyzed by the enzyme phenylalanine ammonia-lyase present in the fungi), and in turn convert it to styrene (a reaction catalyzed by cinnamic acid decarboxylase) (Pagot et al. 2007).

Styrene is an aromatic hydrocarbon used as a monomer to produce many plastics, including those used for food packaging. Packaging material is able to release various types of compounds through a phenomenon referred to as "migration," a diffusion process influenced by interactions between the components of food and the packaging materials while at storage temperatures. Indeed, compounds such as methylbenzene, etilbenzene, xylenes, styrene, and 1,4 dichloro benzene have been detected in packaged foods. Among these, styrene has a low maximum concentration level permitted by European legislation $(60 \mathrm{mg} / \mathrm{kg}$ ) (Chiesa et al. 2006). The aim of this study was to estimate the amount of styrene in portions of Gorgonzola designation of origin (DOP) samples packaged in tubs or remained unpackaged to distinguish between styrene produced by Penicillium roqueforti (in vitro) and styrene potentially released from the plastic packaging.

\section{Materials and methods}

Gorgonzola cheese samples were divided into five production batches, stored at $4^{\circ} \mathrm{C}$, and analyzed at the end of the shelf-lives (30 days). Three samples packaged in trays (single slice) and three unpackaged samples of Gorgonzola cheese from each batch were analyzed. Penicillium roqueforti has been isolated from both types of products by sterilely taking a piece of cheese and inoculating fungal mycelium onto specific culture media $\left[\mathrm{M}_{2}(2 \%\right.$ malt $)$ and Czapek Yeast Extract Agar] (Dragoni et al. 1997). In addition, the volatile compounds were extracted from the packaging without cheese in order to verify the presence of styrene. A solid phase microextraction (SPME) technique coupled to gaschromatography/mass spectrometry (GC-MS) was used (Lau and Wong 2000). A fibre coated with divinylbenzene/ carboxen/polydimethylsiloxane (DVB/CAR/PDMS 50/30 $\mu \mathrm{m}$ ) was used. The extraction time was $180 \mathrm{~min}$ at $4^{\circ} \mathrm{C}$. The eluate was analyzed in SIM (single ion monitoring) due to the characteristic ions of styrene $(\mathrm{m} / \mathrm{z} 51,78,104)$. Nitrobenzene was used as an internal standard $(\mathrm{m} / \mathrm{z} 51,77,123)$. To make a calibration curve (intra-matrix) for the quantitative determination of styrene, varying amounts of styrene were added to a Gorgonzola sample. All the analyses were performed in triplicate. 
Table 1 Content of styrene in samples of packaged and unpackaged Gorgonzola cheese (values are expressed as mean $\mathrm{ng} / \mathrm{g}$ )

\begin{tabular}{lll}
\hline Gorgonzola samples & $\begin{array}{l}\text { Gorgonzola unpackaged } \\
\mathrm{ng} / \mathrm{g} \\
(n=3)\end{array}$ & $\begin{array}{l}\text { Gorgonzola packaged } \\
\mathrm{ng} / \mathrm{g} \\
(n=3)\end{array}$ \\
\hline Batch 1 & 137.98 & 678.88 \\
Batch 2 & 239.62 & 727.58 .00 \\
Batch 3 & 227.45 & 802.53 .00 \\
Batch 4 & 218.52 & 701.75 \\
Batch 5 & 250.00 & 609.25 .00 \\
\hline
\end{tabular}

\section{Results}

The content of styrene in the analyzed samples is presented in Table 1 . The calibration curve used for the quantitative analysis had a good linearity $\left(\mathrm{r}^{2}=0.999\right)$. Figure 1 represents the chromatogram concerning the analysis of empty box packaging.

\section{Discussion}

The content of styrene in packaged samples of Gorgonzola cheese is higher than that found in unpackaged ones, although still below the maximum limit permitted by EU law for this compound $(60 \mathrm{mg} / \mathrm{kg})$. Evaluation of the volatile compounds of the container used for packaging (empty) has been satisfactory in that styrene was detected. Therefore, this study concluded that the production and subsequent styrene content in the samples is due both to the development and production by Penicillium roqueforti used as a "starter" in the preparation of Gorgonzola cheese, and from migration from the plastic material used for packaging. Similar results were obtained in a previous preliminary study that analyzed samples of various types of cheese to evaluate the packaged and unpackaged products

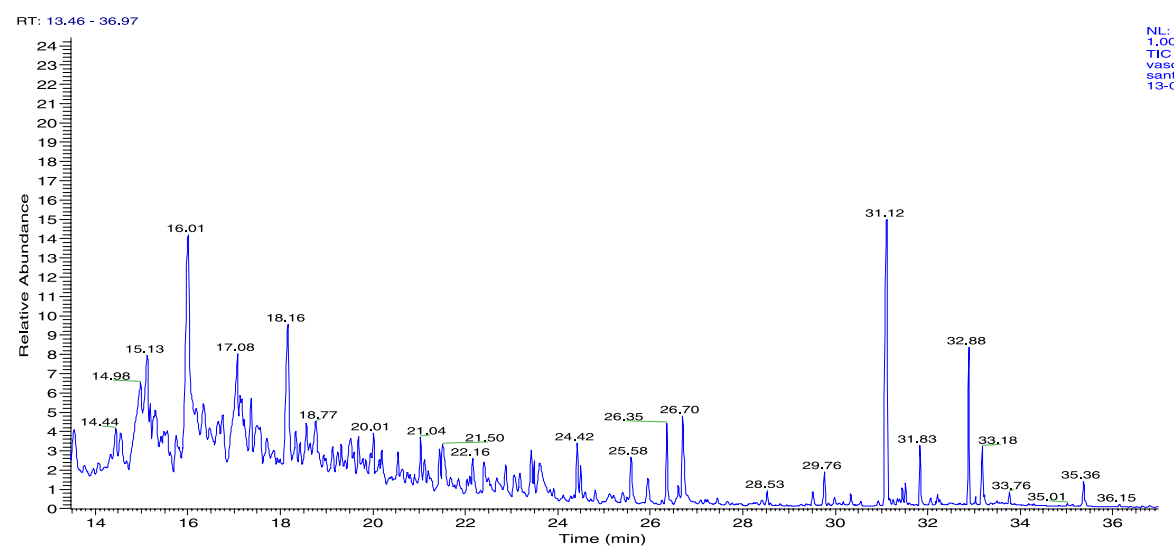

Fig. 1 Total ion chromatogram relative to the analysis of volatile compounds in empty box packaging (styrene retention time 16:01 $\mathrm{min}$ ) 
(Tang et al. 2000). The dangerous effect of styrene is mainly due to its metabolite, the corresponding epoxide, which is recognized in the literature as mutagenic (Flanjak and Sharrad 1984). The obtained results show that, despite that packaged gorgonzola cheese samples have a styrene content less than the legal limit, there is enrichment due to the migration phenomenon from the packaging material.

These results can be used as a basis for the study of new materials with ideal characteristics in terms of migration of toxic substances and to lead to new legal limits that take into account the consumer exposure in terms of chronic toxicity. An additional way to protect products, including Gorgonzola, would be to include a PDO.

Acknowledgements Dr. Sara Panseri was the recipient of a fellowship granted by Regione Lombardia for the project entitled "The packaging of cheese by plastic films: study of release issues and operative conditions during the storage of typical cheeses from Lombardia.” FORTIPACK (cod. 1178)

\section{References}

Adams TH, Yu JH (1998) Coordinate control of secondary metabolite production and asexual sporulation in Aspergillus nidulans. Curr Opin Microbiol 1:674-677

Caridi A (1996) Biotecnologie microbiche ed alimenti: il ruolo delle muffe nella maturazione dei formaggi. Helios Magazine 3(1):24-25

Chiesa LM, Soncin S, Biondi PA, Cattaneo P, Cantoni C (2006) Different fibers for the analysis by solidphase microextraction (SPME) of volatile compounds in processed meat products. Vet Res Comm 30 (Suppl 1):349-351

Dragoni I, Cantoni C, Papa A, Vallone L (1997) Muffe, alimenti e micotossicosi. Ed. Città Studi, Milano 74-78

Flanjak J, Sharrad J (1984) Quantitative analysis of styrene monomer in foods: a limited east Australian survey. J Sci Food Agri 35:457-462

Frisvad JC, Filtenborg O (1989) Terverticillate Penicillia: chemotaxonomy and mycotoxin production. Mycologia 81:837-861

Lau OW, Wong SK (2000) Contamination in food from packaging material. J Chromatogr A 882:255-270

Locci R (1999) La micologia degli alimenti alle soglie del 2000. Informatore Fitopatologico 12:24-32

Pagot Y, Belin J-M, Husson F, Spinnler H-E (2007) Metabolism of phenylalanine and biosynthesis of styrene in Penicillium camemberti. J Dairy Res 74:180-185

Tang W, Hemm I, Eisenbrand G (2000) Estimation of human exposure to styrene and ethylbenzene. Toxicol 144:39-50

Tiecco G (2001) Igiene e tecnologia alimentare. Ed. 24 ore Edagricole, Milano 102-103 